\title{
aniki
}

Revista Portuguesa da Imagem em Movimento

Portuguese Journal of the Moving Image

\section{Arte do corpo, arte do duplo: uma dimensão do imaginário em Jean Rouch}

Philippe Lourdou ${ }^{1}$

Marcius Freire ${ }^{2}$

A Nouvelle Vague começava a dar os seus primeiros passos quando Moi, un Noir veio a público. Era o ano de 1958. Chabrol, Godard, Rohmer, Truffaut e outros começavam a lançar as bases de um movimento cujos filmes, meios de produção, recursos técnicos e formas narrativas iriam ter repercussões inesperadas e transformar, durante alguns anos, a história do cinema francês, com grande impacto na cinematografia ocidental como um todo.

Filmagens em exteriores, recrutamento de atores nem sempre profissionais, utilização de câmeras leves e, por conseguinte, frequentemente na mão, intrigas urbanas... são os principais ingredientes das produções que passaram a ser lançadas pelos jovens cineastas franceses. Na crítica especializada, considera-se que a certidão de nascimento do movimento foi o artigo "Une certaine tendance du cinéma français", de François Truffaut, publicado no n. ${ }^{\circ}$ 31 de janeiro de 1954 dos Cahiers du Cinéma; enquanto Le Beau Serge (1958), de Claude Chabrol, corresponde ao seu registro fílmico. No entanto, para muitos, foi Godard e o seu À bout de souffle (1960) que, efetivamente, apresentaram as lettres de noblesse do movimento. E é aqui que Jean Rouch e o seu Moi, un Noir (1959) vão ao encontro das raízes do movimento, pois muitos veem nas peripécias de Oumarou Ganda em Abidjan uma grande influência nas intrigas vividas por Jean Seberg e Paul Belmondo nas ruas de Paris. A tal ponto que não foram poucos os críticos que identificaram o filme como uma "etnografia da juventude francesa" da época. ${ }^{3}$

Por outro lado, reiterando a declaração de Godard sobre o papel fundamental de Jean Rouch na eclosão da nouvelle vague, mas estendendo sua influência a todo o cinema francês dos anos 1960 e

\footnotetext{
${ }^{1}$ Formation de Recherches Cinématographiques - FRC, Université Paris Nanterre, 92000 Nanterre, France.

${ }^{2}$ Departamento de Cinema, Instituto de Artes, Universidade Estadual de Campinas - Unicamp, 13083-854 Campinas, SP, Brasil.

${ }^{3} \mathrm{O}$ impacto causado pelo filme de Jean Rouch levou Godard a declarar que "Moi, un noir [...] é o mais audacioso dos filmes e ao mesmo tempo o mais humilde. [...] Moi, un Noir, é um francês livre que lança livremente um olhar sobre o mundo livre". (Godard 1959).
} 
1970, Jacques Rivette afirma numa entrevista, em setembro de 1968 , aos Cahiers du Cinéma:

Rouch é o motor de todo o cinema francês nos últimos dez anos, mesmo que poucos saibam disso. Jean-Luc Godard começou a partir de Jean Rouch. De algum modo, Rouch é mais importante que Godard na evolução do cinema francês. Godard vai numa direção que só é válida para ele mesmo, e que, na nossa opinião, não é exemplar. Enquanto que todos os filmes de Rouch são exemplares. (Jacques Rivette cit. in Aumont 1968)

Nas páginas que seguem, vamos procurar apontar algumas das principais características do cinema de Jean Rouch, sublinhando as noções e conceitos por ele desenvolvidos que conformaram a sua obra e partilharam novos modos de realização fílmica.

\section{O cineasta e o seu duplo}

Todos aqueles que tenham se interessado pela personalidade, pela trajetória e pela obra de Jean Rouch sem dúvida observaram, tanto nos seus textos quanto nas numerosas entrevistas que concedeu mundo afora, a presença da sua pessoa - no mínimo, sob a forma de um "eu" - e alusões ou evocações de episódios de sua vida pessoal ou profissional. Um exemplo marcante dessa presença pode ser encontrado em Chronique d'un été (1960), filme no qual ele aparece e intervém inúmeras vezes, sendo boa parte delas, convém ressaltar, em companhia de Edgar Morin, co-realizador da obra.

Mas essa participação bastante esporádica, através da qual ele se torna, no mais das vezes de forma furtiva, um personagem de seus filmes, se revela talvez para ilustrar aquele princípio assaz conhecido segundo o qual o observador faz parte do processo observado. Tratarse-ia, em suma, apenas de materializar de maneira direta, de afirmar concretamente essa presença sobre a qual ninguém poderia duvidar, pois o realizador nunca procurou dissimulá-la,

Como sabemos, uma parte importante dos temas dos filmes etnográficos realizados por Jean Rouch pertence ao campo do sagrado. Nesse campo, os rituais são o objeto privilegiado de sua atenção. Talvez aqui esteja uma das características mais marcantes a ser investigada em sua obra, pois sua inclinação por cerimoniais ritualísticos pode, a nosso ver, estar relacionada à sua inaptidão em investir na materialidade ordinária dos seres. $\mathrm{Na}$ verdade, ele nunca abordou um assunto concernente, sob qualquer aspecto, à vida quotidiana. Até onde sabemos, ele se manifestou pouco a esse respeito, mas podemos, no entanto, destacar a seguinte frase em que ele lamenta não ter realizado um filme tratando desse tipo de tema, particularmente o da infância: "Penso que sobre esse assunto eu jamais fiz os filmes que deveria ter feito. Essas relações da vida familiar, da vida doméstica, são para mim os temas mais difíceis. Eu gostaria muito de filmá-los, mas eu não sei fazer isso" (Gallais 1981, 
13). De certa maneira, talvez isso não lhe conviesse, uma vez que a vida quotidiana é quase sempre uma matéria que se reveste de uma aparência instável e que raramente guarda virtudes manifestamente espetaculares. E é aí que poderia residir a fonte de sua predileção pelo mundo do rito. Ao mundo do rito ou do cerimonial está invariavelmente associado o espetáculo, no sentido lato do termo, ao qual se associa igualmente a visão. Trata-se de um conjunto no qual todos os participantes, destinadores e destinatários tornam-se protagonistas e cumprem o seu duplo papel de verem e de serem vistos. ${ }^{4}$

É sabido que todo rito, qualquer que seja ele, evolui no tempo e no espaço segundo um programa preconcebido que, geralmente, não admite modificação no seu desenrolar, a não ser de forma muito excecional. Aquilo a que se chama "programa" pode evocar, obviamente, a ideia de roteiro tal qual a entendemos no mundo do cinema. Essa estrutura preexistente, presente em qualquer ritual, individual ou coletivo, que poderíamos qualificar de "roteirística", se presta plenamente a um tratamento cinematográfico. Para Jean Rouch, o trabalho amparado na tradição oral de seus personagens não possibilita a escrita de roteiros e, muito menos, o desenvolvimento de diálogos. Então, diz ele: "sou obrigado a me submeter a essa improvisação que é a arte do logos, a arte da palavra e a arte do gesto. É necessário disparar uma série de ações para ver, de repente, emergir a verdade da ação inquietante de um personagem que se tornou inquieto" (Rouch 1981, 8).

Perguntamo-nos, então, por que razão os rituais atraem tanto os realizadores de filmes etnográficos. Parece-nos que isso não se deve unicamente ao aspecto colorido e hierático dessas manifestações, frequentemente acompanhadas de música e dança. Queremos crer que um dos motivos mais importantes parece encontrar-se na organização programática que é uma de suas principais propriedades e que redunda quase sempre numa linearidade. O cineasta pode, desde logo, apoiar-se sobre esse equivalente de um roteiro e seguir as suas etapas na ordem obrigatória que ele determina.

O que quer que seja que venha a ser imaginado, e quaisquer que venham a ser as reais motivações de Jean Rouch no campo da etnografia, os ritos que ele abordou, como aliás qualquer rito, apresentam a particularidade de mostrar corpos em que se manifestam imediatamente, ou quase, uma atitude gestual e postural de caráter fortemente coreográfico, uma vez que, no final das contas, é lícito pensar que o comportamento ritual é um fenômeno que se inscreve e se encarna - quase necessariamente, poderíamos dizer numa coreografia.

Por sua vez, o cineasta - para não dizer de maneira mais geral, o observador - se inscreve quase sempre como um personagem da

\footnotetext{
${ }^{4}$ A esse respeito podemos citar a observação feita por Marcel Mauss ao evocar certos ritos australianos: "Faz-se um gesto não apenas para agir, mais ainda para que os outros homens e os espíritos o vejam e o compreendam" ([1921] 1969, 122).
} 
cerimônia a qual ele procura apreender e dela prestar contas com o instrumento cinematográfico. Às vezes, é mesmo levado a isso sem estar plenamente consciente de sua ação no momento em que registra as imagens. Essa observação é bem ilustrada em um dos filmes do realizador (Yenendi de Ganghel, 1968) em que se pode ver alguns protagonistas de um ritual, possuídos por uma entidade, virem até o cineasta e apertarem a sua mão. O observador-cineasta sai, então, dos bastidores e participa de forma explícita do desenrolar do ritual e, até mesmo, de sua coreografia. É assim que o realizador segue os corpos dos participantes, em transe ou não, e qualifica seu comportamento de "estranha coreografia" que, de forma por vezes invisível ou ausente, o transforma, juntamente com o técnico de som, em "participante da cerimônia em curso" (Rouch 1973).

A maneira muito pessoal de filmar do cineasta certamente não é estranha a essa impressão de coreografia que emana de alguns de seus filmes. E, sem propriamente dançar, mas filmando dançarinos, o corpo do cineasta deixa-se levar pelos movimentos e pelo ritmo dos seus corpos que, em uma espécie de irradiação, se propagam e vão se imprimir no suporte cinematográfico. De maneira mais geral, podemos adiantar que, de fato, em um filme, duas coreografias se encontram e se fundem: aquela das pessoas filmadas, sendo elas dançarinas ou não, e aquela do cineasta que filma, deslocando-se, ou não, no espaço. A essa estratégia bem particular de participação de certo modo harmoniosa com os movimentos do ritual, o cineasta opunha uma outra, aquela da câmera que incomoda, aquela em que a fusão das coreografias se transforma em choque de movimentos, em confronto, em provocação. Então, conforme explica, a câmera se torna um instrumento de agressão: "essa câmera agressiva, eu e mais alguns, como Beauviala e Blanchet, chamamos de 'câmera de contato'. A partir do momento em que filmamos com objetivas grandeangulares, ficamos muito perto das pessoas filmadas e, então, nesse momento, se somos nós mesmos a empunhar a câmera, se fazemos mise-en-scène, alguma coisa acontece e a agressão se torna estimulação" (Rouch 1980, 46).

Mas, se filmar uma pessoa torna-se então, de alguma forma, a expressão de um pas de deux, devido a uma curiosa e singular exacerbação, Jean Rouch parece estar reivindicando que sua pessoa, enquanto cineasta, se assemelha àquela do tyarkaw - o feiticeiro devorador de almas dos songhay -, ao comparar a operação do registro imagético cinematográfico com a caça ao duplo à qual se dedica este último.

Pode parecer tanto desconcertante quanto enigmático, por parte do cineasta, vincular a sua figura àquela, a priori negativa, do feiticeiro songhay identificado como "feiticeiro devorador de alma", ou seja, segundo a crença songhay, aquele que engole o duplo ou mesmo rouba a alma de uma pessoa, o que leva à morte desta última. Curiosamente, ele abandona a figura do sohantye, ou seja, do mágico que representa, no mundo religioso songhay, o inverso positivo do feiticeiro, uma vez que ele também entretém vínculos com o mundo dos duplos, vínculos de proteção que o conduzem, 
consequentemente, a combater o feiticeiro. Com efeito, se o feiticeiro tyarkaw é levado a devorar ou raptar o bia $^{5}$ de uma pessoa, a privá-la de sua alma ou de seu duplo, uma das atividades principais do mágico sohantye consiste em se contrapor à ação maléfica do feiticeiro, a liberar de sua influência a alma ou o duplo cobiçados. ${ }^{6}$

Sem se preocupar em responder à questão de saber porque ele associa a persona do cineasta preferencialmente à do feiticeiro predador de alma - inclusive, isso é para ele uma "analogia" -, Rouch fornece, no entanto, certas precisões que permitem adiantar alguns elementos de resposta. Assim, aos olhos das pessoas filmadas, a pessoa do cineasta que filma se torna uma outra, ela "se metamorfoseia diante dos seus olhos durante as filmagens: ele [o cineasta] agora fala apenas para dar ordens incompreensíveis ("Câmera! Corta!"...)" (Rouch 1973, 542). Ele adota um novo comportamento, bem distante daquele que tem em sua vida normal. Em certo sentido, ele se desdobra na imagem do mágico ou do feiticeiro. Ele se torna seu próprio duplo, ao mesmo tempo ele próprio e seu próprio bia. E, ao se desdobrar, ele vai, por sua vez, produzir outros duplos pois, como ele diz, o cinema é uma "arte do duplo" (Gallais 1981, 32).

Podemos nos perguntar qual é o sentido atribuído pelo cineasta à palavra "duplo". Em outros termos, de que duplo está-se falando, qual é a sua natureza? Devemos ver nele o equivalente do bia songhay, ou seja, um bia cinematográfico que o cineasta - espécie de feiticeiro tyarkaw ao qual ele se compara - caça pelo simples fato de filmar? ${ }^{7} \mathrm{Ou}$ o duplo ao qual ele faz aqui alusão é um simples reflexo da realidade que se oferece à câmera? Enfim, em que mundo evolui, então, o cineasta, dividido entre um mundo ao qual ele atribui um destino profílmico e aquele fabuloso e inquietante da feitiçaria? Mas, para além dessas interrogações, às quais não se prestam as respostas simples e claras que poderíamos esperar, o duplo, quer dizer, o bia, não seria ele igualmente a personificação do mundo do sonho? Com efeito, Paul Stoller, ao enumerar os diversos constituintes da persona songhay, precisa que os sonhos são o produto das aventuras noturnas do duplo: "Os anciãos songhay dizem que o ser humano é constituído de carne (ga), de forma vital (hundi), e do duplo (bia). Sonhos são resultado das aventuras noturnas dos duplos" (Stoller 1992, 87).

Então, poderíamos ser levados a pensar que se o duplo está na origem do sonho ou dos sonhos, a predileção inesperada e aparentemente provocadora de Jean Rouch, de se comparar ao feiticeiro "comedor de alma" ao invés do mágico, fica esclarecida. Uma vez que nos leva a compreender que, assim como o feiticeiro, ele busca capturar sonhos, não para devorá-los, mas para mostrá-los e,

\footnotetext{
${ }^{5}$ A noção de bia engloba várias entidades dentre as quais a do duplo e da alma. (Rouch 1973, 531). Encontramos também essa palavra ortografada sob a forma biya (Cf. Rouch 1989, 306).

${ }^{6}$ No que diz respeito ao mago sohantye e ao feiticeiro tyarkaw ver Rouch 1989, 299 313; Rouch 1973, 533-535.

7 “... esta caça às imagens não seria comparável à caça às almas do feiticeiro que eu conservo com cuidados extraordinários (obscuridade, seca, temperatura baixa), é um conjunto de reflexos, um conjunto de reflexos de duplos" (Rouch 1973, 542).
} 
melhor ainda, pedindo emprestado os seus próprios termos, para compartilhá-los (Rouch 1981, 32). Ao fazer isso, ele penetra e explora esta "quarta dimensão" à qual sempre fazia alusão: o imaginário. Com efeito, "o cinema, arte do duplo é, desde já, a passagem do mundo real ao mundo do imaginário, e a etnografia, ciência dos sistemas do pensamento dos outros é uma travessia permanente de um universo conceitual a um outro, ginástica acrobática em que escorregar é o mínimo dos riscos" (Rouch 1981, 31).

\section{Uma coreografia selvagem}

Se insistimos na ideia do inevitável componente coreográfico próprio a cada rito, componente sobre o qual vem se enxertar a atitude cinematográfica de Jean Rouch, parece-nos legítimo citar um de seus filmes para que possamos ilustrá-lo. Encontramos um ótimo exemplo em Tourou et Bitti (1971). Esse filme, rodado em Simiri (República do Níger), onde o cineasta filmou com bastante frequência, é constituído de um plano-sequência ao qual foi acrescentado um plano de introdução, suporte do começo do comentário que indica as circunstâncias e os motivos do registro fílmico. Na sua origem, o filme foi realizado como um testemunho sobre a cerimônia de possessão propiciatória - organizada para obter a proteção das divindades para as colheitas futuras -, que não foi coroada de sucesso por três dias, uma vez que ninguém havia recebido um espírito, e, durante a qual, dois tambores arcaicos, chamados, respectivamente, de Tourou e Bitti, vão participar; instrumentos que o cineasta tem dúvida a respeito de sua utilização futura, uma vez que os considera ameaçados de extinção. Após o plano de introdução, o realizador apresenta, ao som de um violino monocorde (godye), os lugares em que se desenrola a cerimônia, e, em seguida, alguns dos protagonistas, dentre os quais se encontra o agricultor Sambou Albeydou, que se dirige à orquestra em meio à qual se encontram os tambores arcaicos. A câmera segue o agricultor e filma, com uma certa insistência, os dois instrumentos. De repente a música é interrompida e o cineasta pensa em também parar, tanto por acreditar que a cerimônia está quase terminando, quanto porque já havia conseguido fazer um registro visual e sonoro dos dois instrumentos que, aparentemente, estavam fadados a um desaparecimento próximo.

No entanto, alguns segundos mais tarde, os tambores e o violino monocorde retomam suas atividades, enquanto Sambou Albeydou, em frente à orquestra, entra em transe possuído pelo espírito Kure (o "açougueiro Hausa”, "a hiena”). Em seguida, ele atravessa várias vezes a pequena praça em passos largos, dirige-se ao centro em que se encontram os dançarinos e interpela Daouda Sorko, filho do $\mathrm{Zima}^{8}$ Sido, oficiante responsável pela cerimônia. Ele lhe diz que quer ir embora, enquanto o filho do zima recusa o seu pedido e lhe responde pedindo que as colheitas sejam boas. Durante esse tempo, o cineasta se demora nos tamborileiros e, em seguida, se volta

\footnotetext{
${ }^{8}$ Sacerdote das danças e dos rituais de possessão (Rouch 1989, 204-209).
} 
para Sambou Albeydou e junta-se à conversa com Daouda Sorko. Este insiste em querer partir e pede carne, o que é interpretado pelo filho do oficiante como um pedido para que se sacrifique um animal.

É no momento em que o cineasta se aproxima perpendicularmente dos dois homens que discutem que aparece, de forma inesperada, saltitando, recuada de alguns metros, a velha Tusinye Wazi possuída pelo espírito Hadyo (a "cativa peule" também conhecida como "a coquete"). Sempre saltitando, ela se desloca em direção à orquestra enquanto o cineasta, que avançava ao encontro de Daouda Sorko e Sambou Albeydou e que a percebeu se aproximando atrás de um dos dois homens que antes a escondia, modifica a sua trajetória, contornando o lavrador pela esquerda para segui-la. Enfim, pouco tempo depois, o cineasta recua um pouco para se distanciar e terminar o seu registro.

Esse curto filme, construído essencialmente sobre um planosequência, oferece um bom exemplo que permite ilustrar as relações que o cineasta mantém com as pessoas filmadas e o valor coreográfico dos fenômenos que ele busca apreender graças às imagens animadas. Se nos debruçarmos particularmente sobre a breve passagem em que a velha Tusinye Wazi entra em cena, ou seja, sai da sombra e aparece inopinadamente atrás de Daouda Sorko, tudo acontece como se esse aparecimento repentino fosse fruto de uma mise-en-scène cuidadosamente ensaiada. O cineasta avança em direção aos dois protagonistas, Tusinye Wazi se apresenta ao olhar da câmera e esta contorna o personagem à esquerda para encontrá-la. Todo esse movimento se realiza com uma grande fluidez, sem hesitação aparente. Com efeito, é o conjunto da sequência de possessão propriamente dita, com aquela do lavrador, que merece receber a mesma apreciação, e mesmo, para dizer a verdade, o conjunto do próprio plano-sequência. Se esse registro não se beneficia, por óbvio, de uma preparação coreográfica stricto sensu, tal como nas comédias musicais, podemos no entanto falar aqui de coreografia selvagem, selvagem porque o rito, apesar de codificado, permanece em parte inesperado; e coreográfico, pois se os ritos de possessão songhay obedecem todos a um modelo geral que lhes é próprio, mas cujos detalhes não são estabelecidos de forma definitiva, o conhecimento adquirido durante muito tempo pelo cineasta, sua familiaridade, lhe permitem se mover com facilidade naquele campo. Em suas próprias palavras: "Eu assisti a várias centenas de cerimônias de possessão (filmei umas vinte) ...” (Rouch 1973, 532).

Façamos aqui um breve parêntese para observar que o cineasta, em seu comportamento de coletor de imagem, não se deixou tentar pela possibilidade de adotar uma atitude que o levasse a dançar ele próprio com os personagens. Sabemos que, quando o cineasta se deixa seduzir pela ideia de imitar quem dança ao filmá-lo, acreditando que, ao assim proceder, estará incluindo um complemento rítmico adequado aos deslocamentos dos dançarinos, os resultados nunca estão à altura de suas expectativas. Com efeito, a lógica da dança e a do registro imagético dificilmente - para não dizer quase nunca - se correspondem a ponto de permitir que atinjam um ponto de fusão 
satisfatório. Quando um dançarino exerce a sua arte, qualquer que seja ela, o cineasta o segue, ele é dependente do personagem. Em suma, pensamos ver aí uma incompatibilidade entre um dançarino e o cineasta, quando este último pratica, essencialmente, como é o caso no filme aqui abordado, um cinema de observação.

Existe um outro elemento que convém levar em consideração, para além do profundo conhecimento que Jean Rouch tinha dos ritos de possessão songhay e do caráter relativamente rígido de seu desenrolar que lhe permitia, em certos casos, antecipar algumas de suas fases ou momentos. Estamos aludindo aqui à utilização do procedimento do plano-sequência, que possibilita apreender de maneira fidedigna e realçar os fenômenos de natureza coreográfica. Como sabemos, isso não é propriamente uma novidade para o realizador. A título de exemplos, citemos Horendi (1972), filme elaborado essencialmente a partir de uma sucessão de planossequência, mas também Le Dama d'Ambara (1974) e, ainda, em um outro domínio cinematográfico, que mistura ficção e improvisação, Gare du Nord (1965), constituído por dois planos-sequência que se encadeiam um ao outro graças a uma passagem em negro, que cria uma continuidade visual perfeita e que lembra o artifício utilizado por Alfred Hitchcock em Festim diabólico (Rope, 1948).

Como ele mesmo esclarece bem no começo do filme, à guisa de introdução, tratava-se de realizar um plano-sequência, testemunha fílmica "em tempo real" de dois tambores arcaicos. Em tempo real - e a expressão é aqui muito importante -, o registro é feito sem interrupção para dar conta, em continuidade, da performance dos tamborileiros. E, claro, restituir a evolução dos personagens da possessão. O plano-sequência, conforme vimos acima, é um procedimento cinematográfico ao qual os realizadores de comédia musical não se privaram de lançar mão, uma vez que ele ressalta e coloca em evidência a continuidade de diversos movimentos - gestos, atitudes, deslocamentos no espaço - efetuados e produzidos pelos dançarinos.

Nessa ótica, o plano-sequência se revela um dos elementos cinematográficos dos mais importantes para apreender e tentar restituir o movimento. Mas ele não é o único. Para ser eficiente, ele deve estar combinado a uma câmera móvel capaz de apreender o movimento quase de improviso. Uma das particularidades de Jean Rouch é, justamente, filmar com a câmera na mão, de com ela se deslocar para se aproximar ou se afastar de um protagonista ou do objeto de sua mirada. Assim, podemos caracterizar sem receio ou, mais precisamente, afirmar que uma das principais singularidades de seu cinema é ser um cinema da mobilidade. 


\section{A antropologia partilhada}

Em um artigo publicado em 1957, François Truffaut vaticinava:

o filme de amanhã não será realizado por funcionários da câmera, mas por artistas para quem rodar um filme constitui uma aventura formidável e exaltante. [...] O filme de amanhã se parecerá com quem o rodou, e o número de espectadores vai ser proporcional ao número de amigos que o diretor possui.

Por uma estranha coincidência, no mesmo ano em que Truffaut escrevia essas linhas, Jean Rouch se encontrava no Níger e dava início a uma aventura "formidável e exaltante", com uma câmera da qual não era funcionário. Com efeito, após ter realizado pelo menos dez filmes documentários na África do Oeste, o diretor convida três amigos, Lam, Illo e Damouré - com este último já havia realizado Bataille sur le grand fleuve, cinco anos antes -, para levarem a cabo um experimento que viria a ser uma pedra de toque na história do filme documentário. De fato, ao estimular os seus companheiros a reproduzirem, para ele e sua câmera, um processo migratório que acontecia milhares de vezes a cada ano entre o Níger e a então Gold Coast, atual Ghana, o diretor reformula radicalmente a fatura dos documentários que vinha fazendo até então, ao deixar de registrar as coisas que estão dadas no mundo histórico - retomando a expressão de Bill Nichols para se referir àquilo que outros chamam simplesmente de "realidade" - para criar coisas nesse mundo e registrá-las.

Ao assim fazer, Jean Rouch vai ao encontro de Flaherty juntamente com Dziga Vertov, seus dois "ancestrais totêmicos" (Rouch 2009) -, e recria, na África do Oeste, um procedimento que este último havia experimentado na região de Port Harrison, na costa leste na baia do Hudson, Canadá, quando da realização do seminal Nanook o esquimó (Nanook of the North, 1922). Flaherty pintou um afresco sobre a vida dos habitantes dessa região gelada do ártico canadense, em estreita colaboração e cumplicidade com Allakariallak, o verdadeiro nome de Nanook. Seus feitos, os desafios que teve de enfrentar no périplo que modelou a reconstituição do quotidiano de uma família Inuit naquela terra inóspita, se deveram a uma estratégia até então sem par na história do documentário. E a viga mestra a sustentar essa estrutura de mise-en-scène era constituída por um conceito que apenas com Jean Rouch viria a ser nomeado: Antropologia partilhada (Anthropologie partagée).

Como se sabe, o procedimento adotado por Flaherty para reconstituir um modus vivendi que já não era mais praticado pelos seus sujeitos, vai ter Allakariallak não apenas como um informante privilegiado, mas também como uma espécie de co-roteirista. Era a partir das conversas entre os dois que as filmagens se realizavam. Ademais, considerando que Flaherty dispunha dos meios técnicos para revelar e copiar a película no local, a cumplicidade entre o 
filmador e o filmado se desdobrou com a presença de um novo ingrediente: a intermediação das imagens em movimento. De fato, as sequências filmadas durante o dia, a partir das suas negociações com Allakariallak ocorridas na véspera, eram reveladas e depois projetadas para a comunidade e por esta comentada. Os elementos colhidos por Flaherty a partir desses comentários iriam ser levados em conta nas filmagens do dia seguinte.

É esse modelo de construção de um filme etnográfico, em que as pessoas filmadas se envolvem na sua construção, que vai inspirar Jean Rouch na realização de Jaguar (1954-1967). Aqui, não se tratou da reconstituição de fatos existentes no mundo histórico, com os agentes do processo representando os seus próprios papéis, mas da invenção de um processo que, é certo, acontecia - como vimos acima - numerosas vezes por ano; ou seja, a migração de habitantes da região do Sahel em direção à então Gold Coast. No entanto, Lam, Illo e Damouré não tinham qualquer intenção de deixar o seu país para fazer fortuna em um outro, no caso, uma possessão inglesa da qual eram vizinhos. Se assim fizeram, foi para criar uma ficção improvisada cujo diretor e chefe de orquestra seria Jean Rouch, mas na qual, assim como Allakaraliarak em Nanook, eles seriam coautores.

O processo de associação de Jean Rouch com as pessoas por ele filmadas não acontece pela primeira vez em Jaguar. De alguma maneira, todos os seus filmes até então resultam de uma interação eficiente e permanente com os seus sujeitos. No entanto, mesmo estando muito próximo e podendo contar com a colaboração destes últimos, tal colaboração não era nem vista, nem ouvida pelos espectadores. Será em Jaguar que, pela primeira vez, o cineasta irá se inserir no centro da narrativa, mesmo que limitando tal presença à banda sonora. ${ }^{9}$ Até então, ele se comportava como uma testemunha de eventos que estavam dados no mundo e que sua câmera iria registrar. Para explicá-los, uma voz over vinha se acoplar posteriormente às imagens captadas, uma vez que o som direto ainda não existia, e a produção de sentido estava completada.

Ora, em Jaguar, a testemunha desaparece, uma vez que não há o que testemunhar; nada estava lá para ser observado. Aquilo que a câmera registra está sendo fabricado à medida em que os personagens da aventura agem no mundo. Por sua vez, o narrador/testemunha de Bataille sur le grande fleuve (1952); Les fils de l'eau (1953) ou Les maîtres fous (1954), filmes concebidos antes de Jaguar e nos quais o comparecimento do diretor se materializa através no relato daquilo que lhe chega através do visor de sua câmera, dá lugar a um personagem da narrativa imagética, pois ele é um dos quatro personagens que constituem o seu fio condutor, mesmo que, diferentemente dos outros três, sua presença, como vimos acima, se dê apenas na banda sonora. ${ }^{10}$

\footnotetext{
${ }^{9}$ Sua presença nas imagens vai acontecer pela primeira vez em A pirâmide humana (La pyramide humaine, 1969). Sobre esse filme, ver Freire \& Daminello 2016.

${ }^{10}$ Nas palavras de Jean-André Fieschi $(1979,73)$, "Rouch, o observador de rituais, cruza a linha para tornar-se um criador de rituais à sua própria maneira”.
} 
Nesta última, vamos encontrar um outro traço distintivo de Jaguar no interior da filmografia de Jean Rouch e que, também, vai imprimir a sua marca na história do documentário. ${ }^{11}$ Trata-se, aqui, do tratamento dispensado à narração que acompanha as imagens. Para entender esse processo é importante sublinhar, desde logo, que ele se deve, em grande parte, ao fato de ter levado treze anos para ser completado. De fato, se, como já mencionado, as imagens de Jaguar foram registradas em 1954, a narração, ela, só foi definitivamente concluída em 1967.

No procedimento utilizado para levar a cabo o comentário da epopeia que estimulou e de que participou, Jean Rouch instalou seus protagonistas diante das imagens e estes comentavam aquilo que viam sobre a tela. Nesses comentários, eles falam deles mesmos na terceira pessoa, como se fossem um "outro", e daqueles "outros" com quem cruzaram na sua travessia até à Côte d'Or na condição de etnógrafos improvisados. Ordenando, pontuando e, de certa maneira, organizando esses "olhares cruzados", o realizador insere a sua própria visão e pontua o relato com um comentário em que a poesia e a descrição estão presentes. Conforme consideramos em uma outra ocasião,

ao colocar os três personagens de Jaguar face às suas próprias imagens com um recuo de dez anos, Rouch estimulou a construção de um discurso que revelou muito da cultura africana a que estes pertenciam e, também, da visão que tinham, tanto de sua própria cultura quanto daquela dos povos que iam encontrando ao longo de seu percurso. (Freire 2007, 61)

Vê-se assim que, em consonância com as linhas que precedem, a ideia de "antropologia partilhada" de Jean Rouch estava ancorada na experiência de Flaherty e a sua cumplicidade com Allakariallak. Ou seja, a "partilha" a que nos referimos encontra seus fundamentos na contribuição deste último para a construção do filme em que era o personagem principal e que, para assumi-lo, teve o seu nome alterado: Nanook; seja aquele habitante do norte (Nanook of the North), seja aquele habitante do norte que era também um esquimó (Nanook, o esquimó).

Para outros, no entanto, o significado de tal partilha não é dado de maneira tão evidente. Dentre estes outros encontra-se Steven Feld, para quem, segundo Bob W. White (2004), em um artigo publicado na revista Hors Champ de 9 de novembro de 2004, existem três tipos de partilha no cinema de Jean Rouch; a partilha do resultado final com os personagens e a sua comunidade (como no caso do Sigui); a partilha

\footnotetext{
${ }^{11}$ No final dos anos 1950, o documentário passava por mudanças importantes em razão, notadamente, das inovações tecnológicas que surgiam, como o som sincronizado direto, as câmeras leves $16 \mathrm{~mm}$ (a francesa Éclair e a americana Auricon) que podiam ser conectadas ao gravador Nagra, surgido à mesma época. Tais inovações redundaram no surgimento do Cinéma Vérité na França e no Direct Cinema nos EUA.
} 
que surge no fenômeno do cine-transe, e o fato de trabalhar em equipe com um método de trabalho coletivo (como no caso de Jaguar).

A nosso ver, tal partilha não se estende para além do processo de construção fílmica, de associação com as pessoas filmadas para daí extrair elementos com os quais trabalhar e dar forma ao produto fílmico final. A nos amparar naquilo que já mencionamos anteriormente, e que foi afirmado pelo cineasta em vários de seus escritos, conferências etc, Flaherty - e o seu Allakariallak - era, juntamente com Dziga Vertov, um de seus ancestrais totêmicos.

\section{O cine-transe}

Em 1973, Jean Rouch põe em circulação um desses "objetos inquietantes" - para usar os seus próprios termos -, de que tanto gostava (Rouch 1973, 542). Trata-se da expressão "cine-transe", uma ideia, para não dizer uma hipótese, apresentada com frequência pelo cineasta para explicar como, em certas situações de filmagem, podemos nos sentir como que transportados por uma inspiração, um impulso interior, algo como o dáimon do Sócrates platônico. Ao interpretar o termo, com o recuo que o tempo de sua formulação nos impõe, o cine-transe nos parece o princípio explicativo de um fenômeno desconcertante e que permanece em grande parte misterioso para qualquer pessoa que por ele possa ser tomada.

Jean Rouch oferece, de forma concisa, a seguinte descrição: "é o estranho estado de transformação da pessoa do cineasta a que chamei, por analogia com os fenômenos de possessão, de cine-transe" (Rouch 1979, 63). Contudo, essa definição lapidar mantém-se bastante enigmática se não procurarmos saber em que consiste a tal transformação à qual ele faz alusão. Para tanto, é necessário nos remetermos à influência dos escritos de Dziga Vertov sobre Rouch, ratificada no prefácio que escreveu para a obra de Georges Sadoul (1971), dedicada ao cineasta russo (Sadoul 1971). ${ }^{12}$ Se não há dúvidas de que ele já conhecia uma grande parte da obra cinematográfica de Vertov é, no entanto, difícil de estabelecer uma data em relação à descoberta dos seus escritos. Não obstante, podemos observar que ele fala do cineasta soviético já em seu artigo a respeito do filme etnográfico (Rouch 1968, 440-447). Nesse texto, ele se refere notadamente à obra de Nikolai Abramov, em que numerosas citações a Vertov são feitas, e também a textos e manifestos publicados em periódicos dirigidos por Georges Sadoul.

Portanto, no artigo em que ele cunha pela primeira vez a expressão "cine-transe", esse termo é acompanhado por observações cujas origens estão nos manifestos de Vertov e podemos ver Jean Rouch pedir emprestada uma parte dessa terminologia para adaptá-la à sua prática e à sua experiência. É assim que ele encontra inspiração no "cine-olho" e no "cine-orelha", já presentes no texto sobre o filme

\footnotetext{
12 Bernard Eisenschitz, organizador do volume, adverte o leitor que Sadoul não finalizou sua obra e para que o livro fosse lançado foram reunidos diversos manuscritos e outros artigos já publicados, mas ainda inéditos.
} 
etnográfico (Rouch 1968, 443), para forjar novos termos. Com esse espírito, ele "cine-vê" quando faz um filme, ele "cine-ouve" quando grava o som, "cine-mexe" quando procura um ângulo ou se desloca, "cine-monta" para evocar a ordem dos planos quando efetua suas tomadas e, enfim, ele "cine-pensa" (541). Dessa forma, Jean Rouch amplia singularmente - perigosamente, poderiam dizer alguns -, e até quase sem querer, o domínio da reflexão cinematográfica transformando-a em um modo de pensamento algo generalizado. De fato, ele chega até a afirmar que

no campo, o simples observador se modifica, ele não é mais, quando trabalha, aquele que cumprimentava os Anciãos na entrada do vilarejo; para retomar uma terminologia vertoviana, ele 'etno-olha', ele 'etno-observa', ele 'etno-pensa', e aqueles que ele tem à sua frente igualmente se modificam, pois a partir do momento em que confiaram nessa estranha visita, eles 'etno-mostram', 'etno-falam', no limite, eles 'etno-pensam' [...]. (543)

De tal modo que não apenas o cineasta, mas também as pessoas filmadas parecem entrar nesse mundo e se apropriar dessa forma de pensar própria à imagem animada. Nessa perspectiva de extensão das faculdades da prática cinematográfica, em que as fronteiras que separam cinema e etnografia parecem fadadas a se abolir, a câmera se torna um personagem, quase uma pessoa, dotada de capacidades de apreensão e de reprodução do mundo, e mesmo de modificação dos componentes humanos. Sendo assim, a câmera teria competências julgadas bem superiores às nossas.

Esses poucos empréstimos terminológicos nos permitem medir a influência e a sedução que Vertov pode ter operado no cineasta. Mas existe, no entanto, um caminho o qual este último sempre se recusou a seguir: ele nunca quis "captar a vida de improviso" como preconizava Vertov e tal como ilustrou em seu filme O homem da câmera (1929). Para Rouch é importante não se esconder ou se dissimular, assumir e afirmar a sua presença e, assim, por mais paradoxal que isso possa parecer, afirmar aquela do Outro.

Evocada a fonte de inspiração que Vertov representou no nascimento da expressão "cine-transe", é importante adiantar que, uma vez "colocada em circulação" ela vai conhecer uma certa fortuna crítica, já que muitos vão dela se apropriar ou ainda se interrogar quanto ao significado que lhe deve ser dado. O cineasta registra suas imagens em estado de transe? Trata-se de uma simples metáfora ou a expressão de um método? As hipóteses ou as respostas apresentadas são inúmeras e sua diversidade é prova da dificuldade que existe em tentar esclarecê-la ou de resolver aquilo que nela ainda permanece um enigma. ${ }^{13}$

\footnotetext{
${ }^{13}$ Baptiste Buob elabora um precioso inventário das principais hipóteses até hoje apresentadas para dar conta do cine-transe (Buob 2017, 186). Por outro lado, no seu texto, ele evita acrescentar uma nova interpretação do conceito.
} 
Tal diversidade de interpretações é tamanha que somos levados a nos questionar sobre essa própria diversidade. Se o desvendamento do sentido dessa expressão, a partir de algumas de suas encarnações cinematográficas, permanece até hoje envolta em mistérios, é legítimo nos perguntarmos se ela não poderia finalmente se aparentar à famosa noção de "significante flutuante" criada por Levi-Strauss (1968, XLIX). Com efeito, como ele mesmo esclarece, se essa noção "é a escravidão de qualquer pensamento finito", ela é também a garantia de toda arte, toda poesia, toda invenção mítica ou estética" (Ibidem). E acrescenta, logo em seguida, que seria conveniente ver nisso o mana: "a expressão consciente de uma função semântica, cujo papel é permitir ao pensamento simbólico ser exercido, apesar da contradição que lhe é própria" (Ibidem). Em suma, ele indica que "a função das noções do tipo mana é de se opor à ausência de significação sem trazer nela mesma qualquer significação especial" (Ibidem). É certo que poderíamos qualificar de duvidoso o paralelo que acabamos de fazer. Acreditamos, no entanto, que ele ilustra, de alguma maneira, aquilo que foi muito bem observado por Baptiste Buob: a multiplicidade de interpretações ou de usos que a noção de cine-transe tem suscitado. Isso porque, o significante flutuante pode ser concebido como um reservatório, suporte de uma pluralidade de significações que não são totalmente excludentes uma em relação à outra e que lhe são atribuídas por diversas fontes interpretativas.

Já que estas últimas não parecem trazer resposta à questão, ao contrário de Jean Rouch, devemos continuar a nos perguntar qual é a origem dessa expressão. Sabemos a enorme atração que a cultura japonesa exercia sobre ele desde a sua mais tenra idade, particularmente por intermédio das estampas, os ukyiô-e (LéviStrauss 2011). Não nos parece absurdo conceber que a expressão "significante flutuante" tenha sido inspirada e forjada no modelo do ukyiô-e, termo que designa as estampas que significam "imagem do mundo flutuante", expressão, ela mesma, que faz eco ao mono no aware - que remonta ao século XVIII e que traduz o sentimento do caráter efêmero da vida e da impermanência de todas as coisas -, e longínqua influência do budismo antigo.

É nessa perspectiva, enfatizando o disparate partilhado entre esses numerosos analistas, naquilo que diz respeito à significação que poderia lhe ser dada, que poderíamos compreender o caráter incerto e talvez voluntariamente indeterminado do sentido da expressão cine-transe. Sua simplicidade e a natureza aparentemente imediata de sua compreensão, não parecem levantar muitas questões, mas se tornou a fonte de muitas hipóteses interpretativas. Adiantemos de pronto que cada uma dessas hipóteses é em grande medida aceitável e vai na direção sugerida por cada autor, mas parece-nos que nenhuma pode englobar ou definir sozinha o núcleo semântico próprio aos aspectos e prolongamentos que a expressão parece guardar.

É algo surpreendente constatar que, quando levado a evocá-lo, o autor do fenômeno por ele chamado de "cine-transe" faça referência apenas ao filme Tourou et Bitti. Podemos nos perguntar, então, se 
existem outros filmes do realizador nos quais ele tenha se sentido, na sua totalidade ou em partes do registro, tomado ou visitado por esse transe que, aliás, ele relaciona diretamente com a criatividade cinematográfica (Rouch in Gallais 1981, 28).

Algumas de suas realizações podem nos vir facilmente à mente, mas com a ressalva de que nós pensamos, em particular, em partes, mais ou menos extensas destas, do que em um filme inteiro. Citemos, dentre outros, Le Dama d'Ambara, Yenendi du Ganghel, La Goumbé des jeunes noceurs, ou ainda Horendi. Alguns outros poderiam ser acrescentados, pois o que não faltam são exemplos.

Mas, se Jean Rouch não tivesse inventado a expressão cinetranse - que chamou a atenção tanto dos espectadores, quando eles tomavam conhecimento da sua existência, quanto, de forma mais previsível, dos inúmeros críticos que foram por ela inspirados - a fim de qualificar o seu comportamento quando da elaboração dos seus registros, se nós não a conhecêssemos, que modificação isso traria à apreensão dos seus filmes? Muito provavelmente nenhuma. Contudo, essa denominação, inteligível ou não, apresenta por si só rasgos de mistério, para não dizer de misticismo, que não podem deixar de atingir a imaginação de todos.

Assim sendo, o fenômeno do cine-transe conserva seu lado enigmático, permanecendo igualmente, como queria o seu autor, um objeto inquietante, o qual acreditamos compreender, mas que persiste em continuar amplamente inapreensível.

Portanto, não correremos o risco de propor uma outra hipótese interpretativa que viria se juntar a numerosas outras, todas admissíveis, como é importante lembrar, nem uma síntese que resolveria em certa medida aquilo que poderia parecer uma espécie de conflito de interpretações. Antes, nossa opção vai ao encontro de uma alternativa que se aparentaria a uma anti-síntese (ou síntese a valor nulo) que deslocaria as questões do campo do significado da expressão cine-transe àquele de sua função. Esta última se reveste, então, de uma pluralidade de interpretações sem hierarquização entre elas, sem qualquer prevalência de uma sobre as outras.

\section{Considerações finais}

Ao que parece, uma das mais fortes aspirações de Jean Rouch foi a de aceder ao mundo do imaginário. A imagem animada constituía, para ele, o meio mais seguro para alcançar esse objetivo produzindo duplos e, "colocando-os em circulação", os quais, uma vez liberados de suas mãos, se propagariam como se propaga comumente qualquer filme. Talvez ele concebesse o cinema como o meio de disseminá-los, tal como a imagem dessa peste de que fala Antonin Artaud, no começo do seu Théâtre et son double (Artaud 1964), a qual, comparando-a ao teatro, podia produzir efeitos tanto benéficos quanto maléficos. Ou ainda, pensava ele, colocar esse imaginário à disposição daqueles que estariam dispostos a dele se aproximar e compartilhá-lo. 
Seja como for, para alcançar esse imaginário, procedimentos apropriados de mise-en-scène e de inserção eficiente junto às pessoas filmadas tinham de ser buscados. Para tanto, como vimos acima, Jean Rouch foi ao encontro dos seus dois "ancestrais totêmicos", Dziga Vertov e Robert Flaherty. De ambos, procuramos, neste artigo, sublinhar aqueles traços mais marcantes presentes em sua obra e os resultados daí advindos. Assim fazendo, jogamos luz sobre a presença dos movimentos de câmera em seus registros, partindo do ritual que se tornou emblemático para o entendimento do "cine-transe" e que deu origem ao filme Tourou et Bitti, les tambours d'avant. Mas, este rápido esboço ficaria amputado de um dos seus traços mais marcantes se a "antropologia partilhada" dele não fizesse parte. De fato, a associação do cineasta com os sujeitos de seus filmes não apenas reata com Flaherty, mas vai ser o trampolim para a eclosão de movimentos do cinema documentário muitos anos depois. Apoiando a nossa escolha nesse tripé, remetemos o leitor a esta declaração do Griot Gaulois.

Para mim, a única maneira de filmar é caminhando com a câmera, conduzindo-a até onde ela é mais eficaz, e improvisando para ela um outro tipo de balé onde a câmera se torna tão viva quanto os homens que ela filma. Aqui encontra-se a primeira síntese entre as teorias vertovianas do 'cine-olho' e a experiência da 'câmera participante' de Flaherty. (...) Então, ao invés de utilizar o zoom, o operador de câmera realizador penetra realmente em seu sujeito, precede ou segue o dançarino, o sacerdote, ou o artesão. Assim, ele não é mais ele mesmo, mas um 'olho mecânico' acompanhado de um 'ouvido mecânico'. É esse estranho estado de transformação da pessoa do cineasta que chamei, por analogia com os fenômenos de possessão, o 'cine-transe' (Rouch 1979, 63).

Graças às estratégias de mise-en-scène e de inserção escolhidas, o instrumento cinematográfico vai permitir a passagem do real ao seu duplo, e o reino do imaginário é alcançado. Assim, acreditamos ter deixado claro que o cineasta, através de suas palavras ou de seus textos, revela o importante papel que representa para a sua obra esta singular faculdade que lhe permite passar sem dificuldade aparente de sua vida, de sua personalidade de etnógrafo e infatigável pesquisador de campo, aos mundos songhay e dogon com os quais ele foi levado a entrar em contato. A assimilação de sua pessoa àquela dos feiticeiros songhay parece-nos suficiente para demonstrar isso. Aqui, sem dúvida, reside um dos mais relevantes constituintes do cerne de seu cinema.

\section{BIBLIOGRAFIA}

Abramov, Nikolai. 1965. "Dziga Vertov". Premier plan - revue mensuelle de cinéma, 35. 
Aumont, Jacques et al. 1968. "Le temps déborde. Entretien avec Jacques Rivette”. Cahiers du Cinéma, 204, setembro, 6-21.

Artaud, Antonin. 1964 [1934]. "Le théâtre et la peste". In Le Théâtre et son double, Euvres complètes, tomo IV. Paris: Gallimard, 19-39.

Buob, Baptiste. 2017. "Splendeur et misère de la ciné-transe". L'Homme. Revue française d'anthropologie, 223-224, novembro, 185-220.

Colleyn, Jean-Paul (org.). 2009. Jean Rouch. Cinéma et anthropologie. Paris: Cahiers du cinéma/essais - INA.

Fieschi, Jean-André. 1979. "Slippages of Fiction". In The Camera and Man - Antropology-reality-cinema: the Films of Jean Rouch, org. Mick Eaton. Londres: British Film Institute.

Freire, Marcius. 2007. "Jean Rouch e a invenção do Outro". Doc Online, Revista digital de cinema documentário, 3, dezembro, 61.

Freire, Marcius \& Daminello, Luiz Adriano. 2016. "La pyramide humaine ou uma crônica colonial africana". O olho da história, 23, novembro, 21-40.

Gallais, Pascal-Emmanuel (org.). 1981. Jean Rouch une rétrospective. Paris: Ministère des relations extérieures - Cellule d'animation Culturelle/ SERDDAV, 1981.

Godard, Jean-Luc. 1959. "Étonnant, Jean Rouch, Moi, un Noir”. Arts, 713, março.

Lévi-Strauss, Claude. 1968. “Introduction à l'œuvre de Marcel Mauss”. In Sociologie et anthropologie. Paris: PUF.

Lévi-Strauss, Claude. 2011. L'autre face de la lune. Écrits sur le Japon. Paris: Le Seuil.

Mauss, Marcel. [1921] 1969. Euvres, vol. II. Paris: Éditions de Minuit.

Pastre, Béatrice (org.). 2010. Découvrir les films de Jean Rouch. Collecte d'archives, inventaire et partage. Paris: Centre National du Cinéma (CNC) - Éditions Scope.

Rouch, Jean. 1968, “Le film ethnographique”. In Ethnologie générale, Encyclopédie de la Pléiade, org. Jean Poirier. Paris: Gallimard, 429-447.

-----. 1973. "Essai sur les avatars de la personne du possédé, du magicien, du sorcier, du cinéaste et de l'ethnographe”. In $\mathrm{La}$ notion de personne en Afrique noire. Paris: CNRS, 529-544.

-----. 1979. "La caméra et les hommes”. In Pour une anthropologie visuelle, org. Claudine de France. Paris: Mouton Éditeur, 63.

-----. 1980. " $5^{\mathrm{e}}$ Semaine des Cahiers. Deux débats. Reportages en images, cinéma direct. L'expérience du terrain”. Cahiers du Cinéma, 315, setembro, 46. 
-----. 1989 [1960]. La Religion et la magie songhay. Bruxelas: Éditions de l'Université de Bruxelles, 337-349.

-----. 1997. Les Hommes et les dieux du fleuve. Essai ethnographique sur les populations songhay du moyen Niger, 1941-1983. Paris:

Éditions Artcom, Collection Regard d'Ethnographe, 211-227.

-----. 2009. “Our Totemic Ancestors and Crazed Masters”. In

Principles of Visual Anthropology, org. Paul Hockings.

Berlim/Nova Iorque: Mouton de Gruyter, 217-232.

Sadoul, Georges. 1971. Dziga Vertov, Paris: Éditions Champ Libre.

Stoller, Paul. 1992. The Cinematic Griot. The Ethnography of Jean Rouch. Chicago: The University of Chicago Press.

Truffaut, François. 1957. "Le Film de demain sera un acte d'amour". Arts, 15 maio. Reproduzido em "Le plaisir des yeux", Cahiers du Cinéma, 1987, p. 223.

White, Bob W. 2004. "Hommage à Jean Rouch: caméra intouchable". Hors Champ, 9, novembro.

\section{FILMOGRAFIA}

Acossado/À bout de souffle. Dir. Jean-Luc Godard. França: Georges de Beauregard, CNC, 1960.

Bataille sur le grand fleuve. Dir. Jean Rouch. França: CNRS Audiovisuel, 1951.

Chronique d'un été. Dir. Jean Rouch e Edgar Morin. França: Argos Films, 1961.

Festim diabólico/Rope. Dir. Alfred Hitchcock. EUA: Alfred Hitchcock, Sidney Bernstein, 1948.

Gare du Nord. Dir. Jean Rouch. França: Les Films du Losange, 1965.

Horendi. Dir. Jean Rouch. França: CNRS, 1972.

Jaguar. Dir. Jean Rouch. França: Les Films de la Pléiade, 1954-1967.

La goumbé des jeunes noceurs. Dir. Jean Rouch. França: CNRS e Les Films de la Pléiade, 1965.

Le Beau Serge. Dir. Claude Chabrol. França: Ajym Films e Coopérative Générale du Cinéma Français, 1958.

Le Dama d'Ambara: enchanter la mort. Dir. Jean Rouch e Germaine Dieterlen. França: CNRS, 1974.

Les fils de l'eau. Dir. Jean Rouch. França: Les Films de la Pléiade, 1949-1951.

Les maîtres fous. Dir. Jean Rouch. França: Les Films de la Pléiade, 1955.

Moi, un noir. Dir. Jean Rouch. França: Les Films de la Pléiade, 1959. 
Nanook. Dir. Robert Flaherty. Estados Unidos: Pathé Exchange, 1922.

O homem da câmera. Dir. Dziga Vertov. URSS: VUFKU, 1929.

Tourou et Bitti, les tambours d'avant. Dir. Jean Rouch. França: CNRS Audiovisuel, 1967. (versão com comentários e acréscimo de um plano de introdução, duração do registro original 8 min 10 sec. 1971).

Yenendi de Ganghel -le village foudroyé. Dir. Jean Rouch. França: Comité du Film Ethnographique, Serddav, 1968. 